\title{
Knowledge, Attitude and Practices on Antimicrobial Resistance and Usage Among Medical Students in A Malaysian Medical University
}

\author{
https://doi.org/10.3991/ijoe.v16i01.12171 \\ Heethal Jaiprakash $\left({ }^{\varpi}\right)$ \\ International Medical University, Kuala Lumpur, Malaysia \\ MAHSA University, Bandar Saujana Putra, Malaysia \\ heethaljp@gmail.com \\ Ameeta Patil \\ Bioclinica Safety and Regulatory solutions, Mysuru, India \\ Sunil Kale \\ Great Eastern Medical School and Hospital, Sarikakulam, India \\ Pallavi R Shidhaye \\ LNMCRC and JK Hospital, Bhopal, India
}

\begin{abstract}
Drug resistance is a fast mounting crisis. Many factors, like the inappropriate use of antimicrobials by prescribing physician, unregulated sale of drugs and self-medication, have been attributed to the increase in the incidence of antimicrobial resistance. Health care professionals are a significant determinant in this regard their in-depth knowledge is essential for rationale antimicrobial usage. The objective of this study is to analyze the knowledge, attitude, and practice of antimicrobial usage and resistance among different years of medical students. This is a cross-sectional questionnaire-based study which was conducted among yr. 1 to yr.5 students. A validated Questionnaire was obtained. The questionnaire assesses the students on their attitude, practice, and knowledge on antimicrobial resistance and usage. The data were analyzed using descriptive statistics. A total of 543 students participated in the study. Antimicrobial resistance was recognized as an essential and serious public health issue in today's era by $92.16 \%$ Year 5 respondents, which was highest among all the years (Year 1-5). The awareness regarding the etiology of cold and flu was observed to be the highest among Year 4 respondents (65.74\%). Only $2.8 \%$ of the total respondents strongly agreed that skipping one or two doses of antimicrobials does not lead to development of resistance. $49.02 \%$ of the year five respondents always consulted a physician before starting an antimicrobial, indicating a good practice. However, when it came to checking the expiry date of antimicrobials before taking it, the Year 1 respondents $(53.95 \%)$ were more particular. The study revealed that some aspects of knowledge regarding antimicrobial resistance and usage were found to be significantly higher among the respondents in the clinical years. The said knowledge was well-reflected in some, but not all of the facets of the respondent's attitude and practice.
\end{abstract}

Keywords - Practices; Antimicrobial usage; Medical students; Malaysia 


\section{Introduction}

Drug resistance is a fast mounting crisis. Many factors like the inappropriate use of antimicrobials by prescribing physician, unregulated sale of drugs and self-medication have been attributed to the increase in the incidence of antimicrobial resistance(Aleykutty, Jayakar, Suresh, Leena, \& Mathews, 2011; Varghese \& Das, 2010). Health care professionals are a significant determinant for correct use of antimicrobials; in this regard their in-depth knowledge is essential for rationale antimicrobial usage. This would help them prescribe antimicrobials intelligently and give a positive message to society. It has been observed that in some countries the medical students start antimicrobial self-medication and prescribe medication to each other and recommend to other people much before they graduate(Bala, Singh, Kaur, P, \& Kohli, 2013). So it is necessary to assess their knowledge, practice and attitude towards antimicrobial use and KAP studies is the best way to do it.

In 2011, WHO set the theme of World Health Day as 'Combat Antimicrobial Resistance: No Action Today, No Cure Tomorrow'(Hsueh, 2011). This shows how big a problem, spurious use of antimicrobials has been. When antimicrobials were first introduced in the 1940's it revolutionized the world of medicine transforming once deadly diseases into treatable ones. They have proven to play a significant role enabling the development of life-saving interventions in medical field where prevention and treatment of secondary bacterial complications are essential. Unfortunately, over the past few decades the use and misuse of antimicrobials have resulted in rapidly increasing levels of antimicrobial-resistant bacteria, leading to a loss of antimicrobial efficacy. This has led to an increased risk of morbidity and mortality (Arias \& Murray, 2009; Cars, Hedin, \& Heddini, 2011). Hence an increased economic burden causing significant strain on patients and healthcare systems worldwide Being a future pillar of the country's health care system the medical students need to have in-depth knowledge on antimicrobial usage and resistance(Bala et al., 2013).

According to the Malaysian Statistics on Medicine 2005, antimicrobials were the most commonly prescribed anti-infective agents by both public and private healthcare sectors with 9.55 defined daily dose (DDD)/1,000 population/day. The penicillin group is the most commonly used, accounting for $47 \%$ of the total use of antibiotics. Malaysia (9.55 DDD/1,000 population/day) has lower antimicrobial usage compared to Greece (31.4), France (28.97), the United States (24.92), Europe (19.04), and British Columbia (17.9), and is comparable to countries with relatively lower antimicrobial consumption such as Austria (12.5), Latvia (11.7) and in the Netherlands (9.78)(Oh et al., 2010).

It has been emphasized that adequate training should be provided to undergraduate medical students regarding proper prescribing, dispensing and the usage of antimicrobials. This is an important measure to promote judicious use of antimicrobials(Steinberg, 2000). There is a lack of studies available from Malaysia, which assesses the knowledge, attitude, and practices on antimicrobial resistance and usage among medical students, hence this study was planned. The objective of the study was to assess the knowledge, attitude, and practice of medical students on antimicrobial use and resistance in a Malaysian university. 


\section{Methodology}

A cross-sectional study was carried out over one and a half months on medical students in a private medical university in Malaysia. The study included students from year 1 to year five who consented to participate in the study. Participants in the study were selected using convenience sampling. Ethical clearance was obtained from the MAHSA University ethical committee. Informed consent was obtained from all the students included in the study. Demographic details were obtained from the participants under the study. A validated questionnaire was administered to all the participants under the study. The questionnaire was extracted from a study conducted in India after obtaining permission from the authors (Khan, Banu, \& K, 2013). The questionnaire consisted of 5 items to test knowledge, 10 for attitude and 4 for practice. The participant's responses regarding knowledge were assessed by responses as true or false. A series of questions which is intended to study the attitude of the participants regarding antimicrobial resistance and usage was administered by using a 5-point Likert scale, whose responses ranged from 'strongly agree' to 'strongly disagree.' Their self-reported practices regarding antimicrobial usage were assessed using a Likert scale which ranged from 'always' to 'never.' All medical students from year 1 to year five who signed the consent form irrespective of gender and age were included in the study. The questionnaire was distributed to all medical students who fell under the inclusion criteria. They were asked to complete the questionnaire anonymously. Descriptive statistics were used, and data were analyzed using SPSS software.

\section{$3 \quad$ Results}

A total of 543 medical students from year 1 to year 5 participated in the study. The mean age of the students was $22.5 \pm 3$ years. Among the 543 students, $36 \%$ were males and $64 \%$ female students.

Table 1. Medical Student's knowledge of antibiotic use and antimicrobial resistance

\begin{tabular}{|l|c|c|}
\hline \multicolumn{1}{|c|}{ Question } & $\begin{array}{c}\text { True Fre- } \\
\text { quency (\%) }\end{array}$ & $\begin{array}{c}\text { False Fre- } \\
\text { quency (\%) }\end{array}$ \\
\hline $\begin{array}{l}\text { Indiscriminate and injudicious use of antimicrobials can lead to ineffective } \\
\text { treatment }\end{array}$ & $507(93 \%)$ & $36(7 \%)$ \\
\hline $\begin{array}{l}\text { Indiscriminate and injudicious use of antimicrobials can lead to increased } \\
\text { adverse effects }\end{array}$ & $479(88 \%)$ & $64(12 \%)$ \\
\hline $\begin{array}{l}\text { Indiscriminate and injudicious use of antimicrobials can lead to exacerbation } \\
\text { or prolongation of illness }\end{array}$ & $448(83 \%)$ & $95(17 \%)$ \\
\hline $\begin{array}{l}\text { Indiscriminate and injudicious use of antimicrobials can lead to the emer- } \\
\text { gence of bacterial resistance }\end{array}$ & $509(94 \%)$ & $34(6 \%)$ \\
\hline $\begin{array}{l}\text { Indiscriminate and injudicious use of antimicrobials can lead to an additional } \\
\text { burden of medical cost to the patient }\end{array}$ & $486(90 \%)$ & $57(10 \%)$ \\
\hline If taken too often, antimicrobials are less likely to work in the future & $483(89 \%)$ & $60(11 \%)$ \\
\hline Bacteria are germs that cause common cold and flu. & $285(52 \%)$ & $258(48 \%)$ \\
\hline \multicolumn{2}{|c|}{ Antimicrobial Resistance is: } & $61(11 \%)$ \\
\hline An important and serious public health issue facing the World. & $482(89 \%)$ & . \\
\hline
\end{tabular}




\begin{tabular}{|c|c|c|}
\hline An important and serious public health issue in our Country. & $451(83 \%)$ & $92(17 \%)$ \\
\hline An important and serious public health issue in our Hospital & $461(85 \%)$ & $82(15 \%)$ \\
\hline \multicolumn{3}{|c|}{ Cause of Antimicrobial Resistance: } \\
\hline Use of antimicrobials for self-limited nonbacterial infections & $423(78 \%)$ & $120(22 \%)$ \\
\hline Use of antimicrobials with a broader than necessary spectrum & $400(74 \%)$ & $143(26 \%)$ \\
\hline Use of antimicrobials for shorter than the standard duration & $400(74 \%)$ & $143(26 \%)$ \\
\hline Poor infection control measures & $401(74 \%)$ & $142(26 \%)$ \\
\hline Use of antimicrobials for self-limited bacterial infections & $486(75 \%)$ & $137(25 \%)$ \\
\hline Empirical antimicrobial therapy (best guess therapy) & $354(65 \%)$ & $189(35 \%)$ \\
\hline Mutational and evolutionary changes in the microorganism & $496(91 \%)$ & $47(9 \%)$ \\
\hline Lack of restrictions on antimicrobial usage & $478(88 \%)$ & $65(12 \%)$ \\
\hline Excessive antimicrobial use in livestock (Animals reared for food) & $389(72 \%)$ & $154(28 \%)$ \\
\hline Use of antimicrobials for longer than the standard duration & $387(71 \%)$ & $156(29 \%)$ \\
\hline
\end{tabular}

As shown in Table 1, the knowledge regarding antimicrobial use was good among the students. $52 \%$ of the students felt that common cold is caused by bacteria which was not a good finding for medical students. The knowledge of antimicrobial resistance was right among the medical students (Table 1).

Table 2. Medical Student's attitude on antimicrobial use

\begin{tabular}{|l|c|c|c|c|c|}
\hline \multicolumn{1}{|c|}{ Question } & $\begin{array}{l}\text { Strongly } \\
\text { Disagree }\end{array}$ & Disagree & $\begin{array}{c}\text { Undecid- } \\
\text { ed }\end{array}$ & Agree & $\begin{array}{c}\text { Strongly } \\
\text { agree }\end{array}$ \\
\hline $\begin{array}{l}\text { When I have a cold, I should take antimicrobials to } \\
\text { prevent getting a more severe illness. }\end{array}$ & $112(21 \%)$ & $218(40 \%)$ & $69(13 \%)$ & $121(22 \%)$ & $23(4 \%)$ \\
\hline $\begin{array}{l}\text { When I get a fever, antimicrobials help me to get } \\
\text { better more quickly. }\end{array}$ & $80(15 \%)$ & $179(33 \%)$ & $81(15 \%)$ & $176(32 \%)$ & $27(5 \%)$ \\
\hline $\begin{array}{l}\text { Whenever I take an antimicrobial, I contribute to the } \\
\text { development of antimicrobial resistance. }\end{array}$ & $29(5 \%)$ & $149(27 \%)$ & $132(24 \%)$ & $188(35 \%)$ & $45(8 \%)$ \\
\hline $\begin{array}{l}\text { Skipping one or two doses does not contribute to the } \\
\text { development of antimicrobial resistance. }\end{array}$ & $139(26 \%)$ & $188(35 \%)$ & $97(18 \%)$ & $105(19 \%)$ & $14(3 \%)$ \\
\hline $\begin{array}{l}\text { Antimicrobials are safe drugs; hence they can be } \\
\text { commonly used. }\end{array}$ & $100(18 \%)$ & $216(40 \%)$ & $89(16 \%)$ & $121(22 \%)$ & $17(3 \%)$ \\
\hline I stop antimicrobials when I feel better. & $161(30 \%)$ & $198(36 \%)$ & $40(7 \%)$ & $103(19 \%)$ & $41(8 \%)$ \\
\hline $\begin{array}{l}\text { I usually keep antimicrobials stocked at home, in case } \\
\text { of an emergency. }\end{array}$ & $133(24 \%)$ & $171(31 \%)$ & $60(11 \%)$ & $131(24 \%)$ & $36(7 \%)$ \\
\hline $\begin{array}{l}\text { I use left-over antimicrobials from the past prescrip- } \\
\text { tion. }\end{array}$ & $198(36 \%)$ & $171(31 \%)$ & $44(8 \%)$ & $100(18 \%)$ & $30(6 \%)$ \\
\hline $\begin{array}{l}\text { I take antimicrobials according to the instructions on } \\
\text { the label. }\end{array}$ & $15(3 \%)$ & $23(4 \%)$ & $26(5 \%)$ & $253(47 \%)$ & $226(42 \%)$ \\
\hline $\begin{array}{l}\text { I usually look at the expiry date of antimicrobials } \\
\text { before taking it. }\end{array}$ & $14(3 \%)$ & $32(6 \%)$ & $32(6 \%)$ & $210(39 \%)$ & $255(47 \%)$ \\
\hline
\end{tabular}

As shown in Table 2, the attitude of the medical students regarding the use of antimicrobials was right. 
Table 3. Medical Student's practice on antimicrobial use

\begin{tabular}{|l|l|l|l|l|l|}
\hline \multicolumn{1}{|c|}{ Question } & 1-Never & 2-Seldom & $\begin{array}{c}\text { 3- } \\
\text { Some- } \\
\text { times }\end{array}$ & 4-Usually & $\begin{array}{c}\text { 5- } \\
\text { Always }\end{array}$ \\
\hline \multicolumn{2}{|c|}{ P1. The Doctor prescribes a course of antimicrobial for you. } \\
better:
\end{tabular}

Table 3 shows the practices they have on antimicrobial use. Only $20 \%$ do not prefer to take antimicrobials when they have a cough and sore throat. The practices the students followed when they used antimicrobials for themselves were satisfactory.

\section{Discussion}

Medical students, after the completion of their course, will enter the global health workforce and become important stakeholders of health care around the globe. As they learn the recent advances in health care, they will also be exposed to problems, and antimicrobial resistance is one of them. It is essential to understand the knowledge, practice, and attitude of our future doctors in antimicrobial use to prevent unhealthy antimicrobial prescribing habits so that resistance can be avoided. Young doctors should be given more education during their undergraduate training regarding antimicrobial resistance and appropriate prescribing. This is a crucial time during which the importance of these issues should be emphasized. Once these students become qualified it is challenging to change their deeply entrenched views and behaviors(Simpson, Wood, \& Butler, 2006).

A study in the UK showed that by educating undergraduates and graduates on antimicrobial prescribing and resistance, quality of future antimicrobial prescribing could improve(Simpson et al., 2006). Many factors like inappropriate use of antimicrobials, not following the instructions of the prescribing physician, unregulated sale of medication and self-medication have be attributed to antimicrobial resistance(Aleykutty et al., 2011; Varghese \& Das, 2010).In our study we found that the knowledge regarding the indiscriminate and injudicious use of antibiotics was good among our students. This could be because with the advent of social media the students have access to information apart from academic knowledge. It could also be 
because in our curriculum we assess the student's knowledge on antimicrobials all through the five years and not only in one module. As we all know, assessment drives learning, and hence they read the topic for every exam and eventually improve their knowledge on antimicrobial use. It was in consensus with a study conducted in India on medical students which also showed that the students had good knowledge on indiscriminate and injudicious use of antibiotics. In the study by Afzal et al., most of the students did not know that bacteria were not responsible for common cold(Khan, Banu, \& K, 2013). We found the same result in our study which was disheartening. This finding was also found in studies conducted by Ritu Bala et al. and James H et al. (Bala et al., 2013; James, Handu, Al Khaja, Otoom, \& Sequeira, 2006). We need to emphasize on the causes of common cold to our students. This is a basic knowledge which every medical student needs to know as this is the common condition they encounter in practice. The knowledge regarding antimicrobial resistance was good among the students which were in consensus with the study conducted by Afzal et al. and also Ibia et al. (Ibia, Sheridan, \& Schwartz, 2005; Khan et al., 2013).

The practice of antimicrobial use was satisfactory, which is not a very good finding because these are all medical students. The study by Afzal et al. also showed an adequate attitude regarding antimicrobial use(Khan et al., 2013). Apart from teaching about prescribing of antimicrobials the protocol on the use of antimicrobial should be an integral part of the undergraduate curriculum. This will help the students to be aware of the good practices so that they can create awareness in the community.

Antibiotic prescriptions for minor upper respiratory infections and acute bronchitis are considered significant contributors to the increasing antibiotic resistance worldwide. Such injudicious antibiotic use could also result in unwanted adverse events, thus further escalating health care costs(Ibia et al., 2005). To decrease unnecessary prescribing of antimicrobials, medical students need to be targeted repeatedly during their education and be taught the value of prescribing antimicrobials with caution(Kållberg, Kand, \& Larsson, 2015).Pharmacology teaching on antimicrobial prescription should be connected to microbiology teaching on infection control(Davey \& Garner, 2007). By not teaching our students the need for judicious use of antimicrobials we are putting our future patients at risk, thus impacting the global health care and the health care economy of the country.

\section{Conclusion}

The study revealed that some aspects of knowledge regarding antimicrobial resistance and usage were found to be good. The said knowledge was well-reflected in some, but not all the facets of the respondent's attitude and practice. Our study gives an overview of the experience, attitude, and practice of antimicrobial use which can be a useful baseline data for educational interventions in undergraduate teaching. Further studies with larger sample size may be necessary to validate our findings.

Limitations of our study: The sample size may not be enough to comment on the whole medical student population in Malaysia. Our study is mainly based on subjective responses and not objectives observations hence may not be full-proof. 


\section{Conflict of Interest}

None

\section{$7 \quad$ Acknowledgement}

We would like to thank all the students who took part in the study. We would also like to thank the Dean, Faculty of Medicine, MAHSA University, and Management MAHSA University, for permitting us to conduct this study.

\section{$8 \quad$ References}

[1] Aleykutty, N., Jayakar, B., Suresh, P., Leena, P., \& Mathews, S. (2011). Effect of regulations on the appropriate use of antibiotics. Int J Pharma Bio Sci, 2, 32-35.

[2] Arias, C. A., \& Murray, B. E. (2009). Antibiotic-resistant bugs in the 21 st century a clinical super-challenge. New England Journal of Medicine, 360(5), 439-443. https://doi.org/ $\underline{10.1056 / \text { nejmp0804651 }}$

[3] Bala, R., Singh, H., Kaur, K., P, G., \& Kohli, K. (2013). Knowledge and attitude towards antimicrobial self-medication usage: a cross-sectional study among medical and nursing students. International Journal of Basic \& Clinical Pharmacology, 2(4), 428. https://doi. org/10.5455/2319-2003.ijbcp20130816

[4] Cars, O., Hedin, A., \& Heddini, A. (2011). The global need for effective antibioticsmoving towards concerted action. Drug Resistance Updates, 14(2), 68-69. https://doi.org/ 10.1016/j.drup.2011.02.006

[5] Davey, P., \& Garner, S. (2007). Professional education on antimicrobial prescribing: a report from the Specialist Advisory Committee on Antimicrobial Resistance (SACAR) Professional Education Subgroup. Journal of Antimicrobial Chemotherapy, 60(suppl_1), i27i32. https://doi.org/10.1093/jac/dkm154

[6] Hsueh, P.-R. (2011). World Health Day 2011-antimicrobial resistance: no action today, no cure tomorrow. Journal of the Formosan Medical Association, 110(4), 213-214. https://doi. org/10.1016/s0929-6646(11)60032-6

[7] Ibia, E., Sheridan, M., \& Schwartz, R. (2005). Knowledge of the principles of judicious antibiotic use for upper respiratory infections: a survey of senior medical students. Southern medical journal, 98(9), 889-896. https://doi.org/10.1097/01.smj.0000177439.89762.ee

[8] James, H., Handu, S. S., Al Khaja, K. A., Otoom, S., \& Sequeira, R. P. (2006). Evaluation of the knowledge, attitude and practice of self-medication among first-year medical students. Medical principles and practice, 15(4), 270-275. https://doi.org/10.1159/000092989

[9] Kållberg, C., Kand, M., \& Larsson, J. (2015). Medical students' views on the current and future antibiotic resistance situation. Sahlgrenska Academy, University of Gothenburg. Available:https://www.reactgroup.org/wp-content/uploads/2016/10/Medical-students'views-on-the-current-and-future-antibiotic-resistance-situation.en .319.pdf

[10] Khan, A. K. A., Banu, G., \& K, K. R. (2013). Antibiotic Resistance and Usage-A Survey on the Knowledge, Attitude, Perceptions, and Practices among the Medical Students of a Southern Indian Teaching Hospital. J Clin Diagn Res, 7(8), 1613-1616. https://doi.org/ $\underline{10.7860 / \mathrm{jcdr} / 2013 / 6290.3230}$ 
[11] Oh, A. L., Hassali, M. A., Al-Haddad, M. S., Sulaiman, S. A. S., Shafie, A. A., \& Awaisu, A. (2010). Public knowledge and attitudes towards antibiotic usage: a cross-sectional study among the general public in the state of Penang, Malaysia. The Journal of Infection in Developing Countries, 5(05), 338-347. https://doi.org/10.3855/jidc. 1502

[12] Simpson, S. A., Wood, F., \& Butler, C. C. (2006). General practitioners' perceptions of antimicrobial resistance: a qualitative study. Journal of Antimicrobial Chemotherapy, 59(2), 292-296. https://doi.org/10.1093/jac/dk1467

[13] Steinberg, I. (2000). Clinical choices of antibiotics: judging judicious use. The American journal of managed care, 6(23 Suppl), S1178-1188.

[14] Varghese, R. T., \& Das, R. (2010). Antimicrobial drug resistance in India, Possible causes. Asian Stud Med J, 1, 151-154.

\section{Authors}

Heethal Jaiprakash works at International Medical University in Malaysia.

Ameeta Patil works for Bioclinica Safety and Regulatory solutions at Mysuru in India.

Sunil Kale works for the Great Eastern Medical School and Hospital at Sarikakulam in India

Pallavi R Shidhaye works for LNMCRC \& JK Hospital in Bhopal of India.

Article submitted 2019-11-01. Resubmitted 2019-12-13. Final acceptance 2019-12-14. Final version published as submitted by the authors. 